\title{
Processo de reinserção familiar: estudo de casos de adolescentes que viveram em instituição de abrigo
}

\author{
Aline Cardoso Siqueira \\ Universidade Federal do Rio Grande do Sul \\ Centro Universitário Franciscano - PR \\ Ana Paula Zoltowski \\ Jaqueline Portella Giordani \\ Taíse Mallet Otero \\ Débora Dalbosco Dell'Aglio \\ Universidade Federal do Rio Grande do Sul
}

\begin{abstract}
Resumo
O objetivo desse estudo foi compreender longitudinalmente o processo de reinserção familiar de três adolescentes que moravam em abrigos. Visitas domiciliares e Entrevistas de Reinserção foram utilizadas com os participantes e um membro da família, durante um período que variou de seis a 18 meses. Os resultados indicaram que as famílias se encontravam em situação de vulnerabilidade; não houve uma preparação dos jovens e familiares para o retorno; e não foi disponibilizado apoio após o desligamento da instituição. Dois dos adolescentes demonstraram satisfação com a reinserção após alguns meses de desligamento, embora a situação de pobreza e baixo desempenho escolar fossem percebidos como problemas pelos participantes. No terceiro caso, problemas na condução da reinserção fizeram com que a adolescente fosse reabrigada. Discute-se a necessidade de políticas públicas e de programas desenvolvidos por profissionais capacitados, em parceria com os abrigos, que visem à promoção da convivência familiar.
\end{abstract}

Palavras-chave: institucionalização; reinserção familiar; políticas públicas.

\begin{abstract}
Family reunification process: case studies of adolescents who lived in shelters. The goal of this study was to longitudinally understand the family reunification process of three adolescents who lived in shelters. Home visits and Reunification Interview were used with the adolescents and a family member, during a time that ranged from six to 18 months. The results highlighted that such families socially vulnerable; there was no family and adolescents preparation for the reinsertion; and there was no support after such process of detachment from the institution. Two adolescents were satisfied with reunification after some months, although the poor conditions and low academic achievement had been perceived as a problem by the participants. On the third case, there were problems to handle reunification and the adolescent returned to the shelter. The need of public policies and programs, develop by able professionals, engaging with the shelters, are discussed, aiming to promotion family reunification.
\end{abstract}

Keywords: institutionalization; family reunification; public policies.

$\mathrm{A}$ institucionalização é uma medida de proteção utilizada sempre que crianças e adolescentes encontram-se em risco, tendo seus direitos fundamentais violados. De acordo com o Estatuto da Criança e do Adolescente (Estatuto da Criança e do Adolescente [ECA], 1990), esta medida deve ser provisória, visto que é direito fundamental de toda criança e adolescente conviver em família e em comunidade.

Desde a implementação do ECA em 1990, o tema da reinserção familiar de crianças e adolescentes abrigados tem assumido mais espaço tanto em fóruns quanto em centros de pesquisa. Inúmeras formas de nomear este processo têm sido encontradas, como desligamento institucional, desabrigamento, 
reintegração familiar, desinstitucionalização, retorno à família/ convivência familiar, reunificação familiar e reinserção familiar (Azor \& Vectore, 2008; Silva \& Nunes, 2004; Siqueira \& Dell'Aglio, 2007). São expressões que se referem ao processo de saída de um abrigo e o retorno à família, podendo ser a de origem, a extensa e a adotiva.

O retorno ao convívio familiar deve ser promovido assim que a família apresentar condições favoráveis para o retorno do jovem, consolidando o caráter provisório dessa medida (ECA, 1990). O artigo 94 dessa legislação preconiza que é obrigação de toda instituição de abrigo promover o restabelecimento e a preservação dos vínculos familiares; comunicar às autoridades jurídicas, periodicamente, os casos em que se mostre inviável ou impossível o reatamento dos vínculos familiares; reavaliar periodicamente cada caso, dando ciência dos resultados à autoridade competente; manter programas destinados ao apoio e acompanhamento de egressos, entre outras determinações. $\mathrm{Na}$ prática, a equipe técnica do abrigo avalia os casos e propõe um plano de desligamento para a família, podendo incluir condições que devem ser alcançadas por esta para que o desligamento ocorra. $\mathrm{O}$ desligamento ocorre a partir da emissão de um parecer ao Juizado da Infância e Juventude favorável ao retorno da criança ou adolescente, depois de avaliadas se as condições propostas foram alcançadas. O juiz, então, julga se este parecer é suficiente para sua tomada de decisão, e, caso precise de mais informações, solicita estudo da família à equipe técnica do Juizado. Em caso de divergência nos laudos, discussões entre a equipe do abrigo e do Juizado são realizadas com vistas a esclarecer o caso. O desligamento ocorre somente com guia de desligamento emitido pelo Juizado da Infância e Juventude. Também é possível que antes que o desligamento seja efetivado, o juizado autorize um período de experiência familiar. No desligamento, a guarda da criança e/ou adolescente é transferida da instituição de abrigo para os familiares responsáveis, e, após o retorno do jovem, visitas de acompanhamento são realizadas pela equipe técnica do abrigo somente por determinação do Juizado (R. Duzzo, comunicação pessoal, 14 de setembro de 2008).

No campo científico, ainda existe uma carência de pesquisas disponíveis na realidade brasileira sobre esse tema, ao passo que em outros países, como Estados Unidos e países da Europa, pesquisas têm sido base de programas de intervenção de retorno familiar há décadas (Davis, Landsverk, Newton, \& Ganger, 1996; Farmer, 1996; Maluccio, Abramczyk, \& Thomlison, 1996; Maluccio, Fein, \& Davis, 1994; Maluccio, Warsh, \& Pine, 1993). A reunificação familiar de crianças e adolescentes é definida como a reunião física e psicológica de crianças e adolescentes, que estavam sob cuidados não-familiares, com suas famílias de origem.

A pobreza tem sido considerada um fator de risco para a saída de jovens de casa, sendo, em muitos casos, o único motivo para o abrigamento e o principal obstáculo para a reinserção familiar (Courtney \& Wong, 1996; Eamon \& Kopels, 2004). O levantamento realizado por pesquisadores do Instituto de Pesquisa Econômica Aplicada [IPEA] junto a abrigos de todo o Brasil (Silva, 2004), indicou que, além da pobreza, a fragilidade, a ausência ou a perda do vínculo familiar, a insuficiência de políticas públicas de apoio à reestruturação familiar, o envolvimento dos pais/cuidadores com drogas e a violência doméstica foram aspectos que dificultam o retorno à família (Silva, 2004).

O estudo de Landy e Munro (1998) mostrou que a preparação prévia das famílias para a reunificação é um elemento facilitador para o sucesso da reinserção familiar. Esta preparação depende essencialmente das características dos casos e dos fatores de risco presentes que devem ser enfrentados, podendo abranger desde a inclusão da família em programas de moradia, educação e alimentação, até o acompanhamento e tratamento de abuso de drogas, de treinamento para parentalidade, entre outros (Marsh, Ryan, Choi, \& Testa, 2006). As visitas freqüentes entre cuidadores/pais e filhos afastados da família têm sido consideradas um poderoso fator para a efetivação da reunificação familiar (Davis, Landsverk, Newton, \& Ganger, 1996; Warsh $\&$ Pine, 2000). Aqueles que receberam visitas periódicas dos pais, visitas que faziam parte de um plano de preservação familiar, tiveram mais chances de voltar para casa (Landy \& Munro, 1998). Destaca-se que o processo é realizado com a participação ativa e concordância da família, sendo este fator fundamental para o sucesso da reinserção familiar. Estas visitas são acompanhadas e planejadas, possuindo objetivos claros e definidos em concordância com os pais. Segundo Pine, Warsh e Maluccio (1993), os pais/cuidadores necessitam de ajuda para aprender como interagir de maneira positiva com seus filhos e como aproveitar esse momento. Além das visitas, cartas e ligações telefônicas entre as crianças e adolescentes abrigados e seus familiares são importantes estratégias para manutenção do vínculo, especialmente para os casos em que as visitas são esporádicas ou inviáveis.

$\mathrm{Na}$ realidade brasileira, o processo de reinserção familiar de crianças e adolescentes passou a ser foco de pesquisas recentemente. Os estudos de Azor e Vectore (2008), Silva e Nunes (2004) e Siqueira e Dell'Aglio (2007) são exemplos de pesquisas sobre este processo no Brasil. Segundo Azor e Vectore (2008), os fatores que contribuíram para o retorno ao convívio familiar de jovens abrigados foram a insistência do Poder Judiciário; o acompanhamento familiar por profissionais; a adequação da moradia; e o desejo dos familiares. Para estas autoras, é necessário conhecer as condições emocionais, a motivação da família e as expectativas relacionadas às crianças e aos adolescentes. O estudo de Silva e Nunes (2004) apontou que após o retorno à família, os jovens acabam sendo inseridos na situação de vulnerabilidade social na qual seus familiares se encontravam. Nesse estudo, os familiares e os egressos dos abrigos apresentavam-se fora do mercado de trabalho formal, desempenhando atividades esporádicas de venda ou limpeza e de recolhimento de papel nas ruas. Já Siqueira e Dell'Aglio (2007), ao focalizar o processo de reinserção de uma adolescente, observaram a existência de inúmeros e expressivos fatores de risco no ambiente familiar. Estes fatores apareceram de forma clara e já estavam presentes antes do desligamento da jovem.

A partir dessas considerações teóricas acerca do tema da reinserção familiar, constata-se a importância de investigar como estes processos têm ocorrido na realidade brasileira. Embora a efetivação do convívio familiar se dê mais freqüentemente com o retorno à própria família, sejam pais biológicos ou membros da 
família extensa, pouco é conhecido sobre a situação e condições de vida dos mesmos nos meses subseqüentes ao desligamento (Bellamy, 2008). Assim, o objetivo desse estudo foi compreender longitudinalmente o processo de reinserção familiar de três adolescentes que viveram em instituições de abrigo.

\section{Método}

\section{Delineamento e participantes}

Este estudo consistiu em uma pesquisa qualitativa e longitudinal, cujo delineamento foi de Estudo de Caso Múltiplo e Embutido (Yin, 2003/2005). O método qualitativo de estudo de caso envolve a coleta sistemática de informações considerando o contexto social, contribuindo para um efetivo entendimento do fenômeno (Berg, 2001). Participaram desse estudo três adolescentes, apresentados com os nomes fictícios de Pedro, Raquel e Rosa. Dois deles são do sexo feminino e um do sexo masculino, e estavam abrigados em instituições governamentais e não-governamentais da região metropolitana de Porto Alegre, RS/Brasil. Os três participantes foram acompanhados por um período de até 18 meses após o retorno à família.

\section{Instrumentos}

Foram utilizadas Entrevistas de Reinserção (Siqueira, 2006) com os adolescentes e um representante da família. Estas entrevistas investigavam aspectos da história individual dos participantes e da família; a institucionalização; e o processo de retorno à família. Todas as informações coletadas nas Visitas Domiciliares e nas conversas informais foram registradas no diário de campo.

\section{Procedimentos e análise dos dados}

Esta pesquisa foi aprovada pelo Comitê de Ética em Pesquisa do Instituto de Psicologia da UFRGS (registro $n^{\circ}$ 07/007) e pelas diretorias técnicas dos abrigos, as quais assinaram o Termo de Concordância. Os casos de desligamento que atendiam ao critério de inclusão estabelecido (tempo de institucionalização mínimo de seis meses) foram indicados pela coordenação dos abrigos. Nos casos de desligamento de irmãos, optou-se por convidar aquele com maior idade. Assim, as famílias e os adolescentes foram contatados e após esclarecimentos sobre a pesquisa, assinaram o Termo de Consentimento Livre e Esclarecido.

No caso de Pedro, foram realizadas 14 visitas domiciliares ao longo de 18 meses; para Rosa foram 13 visitas ao longo de 10 meses e para Raquel, ocorreram três visitas ao longo de quatro meses. Entrevistas de Reinserção foram realizadas com os adolescentes e um familiar aos três, seis e nove meses após o desligamento, na própria casa do participante, exceto no caso de Raquel que participou somente da primeira etapa de coleta de dados (aos três meses de desligamento). As entrevistas foram gravadas e transcritas, as conversas informais e as observações foram sistematicamente anotadas em um diário de campo logo após a realização das visitas e entrevistas. A partir da análise dos dados, foram levantadas três unidades de análise: institucionalização; processo de desligamento; e convivência familiar. A unidade "institucionalização" incluiu aspectos relacionados às características dos abrigos, ao motivo do abrigamento e à percepção dos jovens quanto ao período que estiveram abrigados. $\mathrm{Na}$ unidade de análise "processo de desligamento", dados sobre como o desligamento foi planejado, como os jovens e suas famílias foram preparados para o desligamento e que tipo de apoio foi disponibilizado às famílias foram encontrados. Na última unidade, elementos do cotidiano dos adolescentes na família e na comunidade ao longo dos 18 meses de acompanhamento foram incluídos. Os casos serão apresentados a seguir a partir das unidades de análise descritas.

\section{Resultados}

Caso 1: Pedro era o terceiro filho de seis irmãos. Ele tinha 15 anos e cursava a $8^{\mathrm{a}}$ série do Ensino Fundamental. Chegou ao abrigo aos quatro anos, não tendo desde então contato com seus cinco irmãos, que foram criados por familiares da mãe ou pela nova esposa do pai. Sua referência familiar era a tia paterna. Não tinha contato com o pai e sua mãe faleceu na prisão quando ele estava com cerca de oito anos. Ele possuía uma rotina médica/ hospitalar desde a infância, visto que Pedro era portador do vírus HIV. Recebia um benefício da previdência social em função de sua doença, o que possibilitou o provimento de bens materiais e um sentimento de independência. Pedro lidava com o fato de ser HIV positivo com naturalidade, afirmava que não se sentia diferente ou inferior.

Institucionalização. $\mathrm{O}$ adolescente viveu em um abrigo governamental durante mais de 10 anos. Foi aplicada esta medida de proteção em função da situação de negligência em que se encontrava, tendo sido internado por desnutrição. No momento do abrigamento, sua mãe estava presa por tráfico de drogas, e Pedro estava sob os cuidados do pai. A modalidade de atendimento oferecida era conhecida como abrigo residencial (AR), no qual cerca de 15 jovens são atendidos por funcionários que trabalham em turnos. Entretanto, durante a infância viveu em um abrigo com mais crianças (abrigo institucional), sendo transferido para o AR ainda na infância. Sobre o abrigo e o período de abrigamento, o adolescente falava de maneira distante e pouco afetiva, afirmava que era "normal" viver lá.

Processo de desligamento. Antes do desligamento, Pedro passou a visitar a tia paterna nos finais de semana. Pedro passava os feriados e datas comemorativas com ela. A residência da tia estava localizada distante do abrigo, e a própria instituição o transportava até o local. Seu desligamento foi providenciado pela assistente social do abrigo, com quem Pedro tinha bom relacionamento, e a condição proposta pela equipe do abrigo era a construção de uma "peça" adicional na casa (seu quarto). Durante os meses anteriores ao desligamento, Pedro usou o recurso de seu benefício social para construir essa "peça", sendo desligado logo que seu quarto ficou pronto. Nos primeiros meses de retorno, a assistente social da instituição realizava visitas periódicas, além de manter contato com o adolescente por telefone. Além disso, nas visitas, ela levava alimentos e produtos específicos que o adolescente gostava, e que, na família, ele não tinha mais acesso. Dezoito meses após o desligamento, os contatos com a 
assistente social tornaram-se esporádicos.

Convivência familiar. Na casa da tia, moravam sete pessoas, o adolescente, a tia, o companheiro da tia, três filhos e o marido da filha. A casa era simples, tinha três quartos, uma cozinha e um banheiro. Sua tia não possuía o Ensino Fundamental completo. A tia e seu companheiro não possuíam empregos fixos, a família era mantida por trabalhos eventuais do companheiro da tia, trabalho de limpeza da tia, e recurso advindo de um programa social do Governo Federal. Além disso, a tia era a responsável por receber o benefício do adolescente, e afirmava que o recurso era utilizado para comprar alimentos e vestuário para o adolescente. Durante o período de coleta de dados, Pedro apresentava a certeza de que seu lugar era com sua família e dizia que estar com a tia é melhor que viver no abrigo. Dizia que não sentia saudade do abrigo ou das pessoas que viviam na instituição. Também não manifestava vontade de visitar o abrigo. Dizia que queria muito viver com a tia, estudar na escola dos primos e viver aquela realidade. Após alguns meses de convivência com a família, Pedro começou a ser desobediente e desafiador, dizia que logo que estivesse com 18 anos, ele iria morar sozinho. Este comportamento deixava a tia chateada e era percebido por ela como rejeição. $\mathrm{O}$ adolescente também mostrou dificuldade em respeitar os horários corretos de sua medicação. No entanto, a maior preocupação da tia era o desinteresse do adolescente pela escola, pois estava com baixo desempenho escolar. Por outro lado, tinha amigos na vizinhança e bom relacionamento com os primos. Aos 18 meses de desligamento, Pedro afirmou estar bem e feliz com sua vida. A preocupação de sua tia quanto ao seu desinteresse nos estudos continuava ainda mais forte visto que Pedro foi reprovado na escola.

Caso 2: Rosa era a quinta filha de sete irmãos. Ela tinha 13 anos e cursava a $5^{\mathrm{a}}$ série do Ensino Fundamental. Não tinha contato com o pai biológico e sua mãe possuía problemas mentais, sendo internada freqüentemente. Suas irmãs mais velhas foram criadas por parentes em virtude da doença de sua mãe. Duas de suas irmãs mais velhas possuíam suas próprias famílias e não participavam das questões financeiras e de saúde da mãe. A terceira filha, de 22 anos, era a responsável pela família, tendo buscado de forma ativa o retorno de Rosa e de seu outro irmão de nove anos à família, e assumido a responsabilidade por eles. A irmã mais nova da família, portadora da Síndrome de Down, encontrava-se abrigada na mesma instituição que Rosa estava. Rosa mostrou-se uma adolescente tranqüila e reservada, demonstrava timidez nas conversas, contudo era assertiva nas suas opiniões.

Institucionalização. Rosa esteve abrigada durante seis anos e nove meses em uma instituição governamental cuja modalidade de atendimento era abrigo residencial (AR), localizada em uma região afastada do perímetro urbano de Porto Alegre. A adolescente foi abrigada na infância, juntamente com os irmãos mais novos, a partir de um episódio no qual sua mãe apresentou surto psiquiátrico e foi internada. Rosa recordava-se claramente deste momento, contou que sua mãe se debatia, tirava as roupas e que policiais tentavam segurá-la. A adolescente tinha boas recordações do período em que morou no abrigo, como as boas condições de alimentação e vestuário proporcionadas pela instituição, lembranças de quando cozinhava bolos com as outras meninas e monitoras, comemorações de aniversário, além de cursos e aulas de esporte.

Processo de desligamento. $\mathrm{O}$ desligamento institucional foi buscado pela família da adolescente. Anteriormente ao desligamento, a adolescente realizava visitas à família nos finais de semana. Para o seu retorno e de seu irmão, foi preciso que eles mudassem para uma casa com mais cômodos. A família cumpriu essa exigência, e apesar da nova casa ser maior (havia três quartos), estava em pior estado que a anterior, com danificações no teto e chão. Além disso, estava localizada em uma área muito pobre da cidade, a casa não tinha rede de água e esgoto, a qual foi instalada ao longo desses meses de acompanhamento. A família mostrava-se ressentida com a instituição de abrigo, afirmando que, apesar da família cumprir a exigência de mudar de residência, o abrigo não cumpriu a promessa de ajudar a família com alimentos. Após o desligamento da adolescente, a família não recebeu nenhuma visita ou acompanhamento de profissionais do abrigo ou entidades governamentais com vistas a avaliar e verificar a reinserção.

Convivência familiar. Na casa, moravam a mãe de Rosa, seu padrasto e quatro irmãos. O padrasto mantém uma relação instável com a família, desaparecendo por semanas. No início do retorno de Rosa, a irmã mais velha tinha um emprego fixo em um supermercado do bairro, contudo, em função das internações psiquiátricas da mãe, ela passou a faltar ao trabalho e perdeu o emprego. Nenhum adulto possuía emprego fixo, o padrasto realizava trabalho de biscate, a irmã mais velha vendia produtos de beleza e pastéis em estabelecimentos públicos eventualmente e a mãe recebia um benefício da previdência social, em função de sua doença. Sua mãe não possuía o Ensino Fundamental completo, mas sua irmã de 22 anos possuía. Contudo, não conseguiu terminar o Ensino Médio. Cerca de cinco meses após o desligamento, a família soube que era elegível ao recebimento de recurso de um programa social do Governo Federal, e passou a receber este recurso mensalmente. A renda da família não era o suficiente para o seu sustento, sendo necessário o recebimento de alimentos da comunidade, em especial, da Igreja a qual a família freqüentava. Rosa estava feliz com seu retorno à família, estava se dedicando mais à escola e acreditava que o seu retorno para casa tinha mudado sua vida. A adolescente comentava sobre as diferenças existentes entre sua casa/família e o abrigo. Ela dizia que apesar de no abrigo ela ter acesso a verduras, carne, frutas, entre outros alimentos, ainda assim preferia estar com a família. Aos 18 meses de desligamento, Rosa e sua família não moravam mais na casa em que as visitas foram realizadas, não sendo possível coletar informações sobre a adolescente. A nova moradora informou que a família havia se mudado para uma cidade da região metropolitana de Porto Alegre, na qual alguns parentes já residiam.

Caso 3: Raquel tinha 12 anos e cursava a $7^{\text {a }}$ série do Ensino Fundamental. Foi abrigada pela primeira vez, juntamente com a irmã mais nova, quando tinha cinco anos de idade. Sua mãe 
biológica era "prostituta" e faleceu alguns anos depois. Em concordância com a família de origem das meninas, uma amiga da família paterna de Raquel, motivada pelo desejo de ter filhas, procurou o desabrigamento das irmãs. Na ocasião, segundo a mãe de criação, ela e um tio paterno fingiram ter um relacionamento estável frente à Justiça, a fim de justificar o interesse pelas garotas. Assim, esta senhora tornou-se a mãe de criação das meninas. Ela estava separada do marido e possuía três filhos. A família paterna nunca demonstrou interesse em manter contato com as mesmas.

Institucionalização. O primeiro abrigamento de Raquel ocorreu na sua infância em decorrência do envolvimento de seus pais com tráfico de drogas e subseqüente aprisionamento de ambos. Na segunda vez, a adolescente estava com 11 anos de idade e morava com sua mãe de criação. Problemas de relacionamento entre ela e a mãe de criação fizeram com que ela voltasse ao abrigo. Raquel esteve abrigada durante nove meses em uma instituição governamental cuja modalidade de atendimento era abrigo residencial (AR), localizada em uma região afastada do perímetro urbano de Porto Alegre. A adolescente tem pouca lembrança da primeira vez que foi institucionalizada, visto que tinha poucos anos de idade. No segundo abrigamento, a adolescente afirmava que era um lugar bom para morar, gostava dos educadores e das outras crianças. Durante esse período, a adolescente demonstrava interesse pela escola e tinha muitas amigas.

Processo de desligamento. Antes do desligamento, Raquel passou a visitar a mãe de criação nos finais de semana. A residência da mãe de criação estava localizada na região metropolitana de Porto Alegre, sendo que a própria instituição fornecia os vales transportes para a adolescente ir para casa. Ao final do ano escolar, foi autorizado que a adolescente passasse as festas de fim de ano com a mãe de criação, sendo a adolescente desligada subseqüentemente. A mãe de criação afirmou que esta decisão foi tomada unilateralmente, sem que ela fosse consultada. Ela afirmou que, um dia, a adolescente chegou com todos seus pertences. Em contato com a instituição, foi informada que seria um período de experiência, e que a adolescente ainda poderia ser "devolvida" para o abrigo.

Convívio familiar. Além da mãe de criação, moravam na casa os quatro filhos da mesma e a irmã mais nova da adolescente. Dos três filhos biológicos, apenas o filho mais velho apoiava a permanência da menina. A mãe de criação educou sozinha todos os filhos, sem ajuda do ex-marido. A família era humilde, mas possuía uma condição de vida suficiente para não precisar de ajuda da comunidade. A mãe de criação conseguiu aos poucos ampliar a casa, que era de alvenaria, a partir do recurso de seu trabalho como faxineira de firma e do recurso do seu filho mais velho, que trabalhava em um posto de gasolina. Apesar do emprego fixo, a mãe de criação possuía somente Ensino Fundamental incompleto. A renda familiar ainda era reforçada pelo recebimento de recurso de um programa social do governo federal. O clima familiar passou a ficar tenso após o retorno da adolescente. A mãe de criação mantinha-se atenta aos prazos do período de experiência, para que o retorno da adolescente ao abrigo ainda pudesse ocorrer. Esta postura fazia com que a convivência na família estivesse sendo testada a todo tempo. Assim, a mãe utilizava ameaças de devolvê-la a cada discussão entre as duas. Conforme o relato da mãe, a adolescente desobedecia todas as regras, desde as referentes às roupas que deveria usar para ir à escola, aos horários, às amizades, até as referentes às tarefas domésticas. Além disso, a mãe de criação afirmava que a adolescente tinha "sangue ruim" por ser filha de uma prostituta, acreditando que a menina teria o mesmo futuro que a mãe. Por outro lado, a adolescente não apresentava nenhuma queixa da mãe de criação. Falava sobre as brigas e discussões freqüentes, mas não atribuía muita importância. Ao final de quatro meses de desligamento, a adolescente foi reabrigada no mesmo abrigo em que esteve anteriormente.

\section{Discussão}

Os três casos de reinserção familiar apresentados podem contribuir para o entendimento desse fenômeno, tanto com suas particularidades, quanto com aspectos comuns. Um dos adolescentes participantes deste estudo retornou para a família nuclear (mãe biológica), outro para um membro da família extensiva (tia paterna) e o outro foi residir com pessoas não pertencentes à família co-sanguínea (mãe de criação), uma pessoa que era amiga da família da jovem. As famílias com as quais os adolescentes viviam possuíam dificuldades financeiras (a família de Rosa não tinha, inicialmente, rede de saneamento básico), presença de doença mental, e muitos membros co-habitando a mesma residência. Dois cuidadores não possuíam emprego fixo, todos possuíam baixa escolaridade e recebiam recurso de um programa social de transferência de renda do Governo Federal. Precárias condições econômicas, família numerosa, doença mental, desemprego ou subemprego, baixa escolaridade dos responsáveis pela família são fatores de risco descritos na literatura e características apontadas como freqüentes entre as famílias das crianças e adolescentes institucionalizados (Fonseca, 1987; Rizzini \& Rizzini, 2004; Silva, 2004), como também na realidade brasileira (Instituto Brasileiro de Geografia e Estatística [IBGE], 2002). Além disso, a participação de todas as famílias em um programa de transferência de renda do Governo Federal aponta, por um lado, que este programa tem alcançado as famílias que estão em situação de pobreza, sendo um importante recurso extra nesse processo de retorno à família. Por outro lado, o apoio governamental a estas famílias se resumiu a este recurso, visto que nenhum outro programa do governo foi desenvolvido com as mesmas.

A prática observada no caso de Raquel, na qual crianças e adolescentes são educadas por pessoas que não fazem parte da família nuclear, é chamada de "circulação de crianças", e tem sido destacada como uma prática comum entre as famílias brasileiras (Fonseca, 1987). Indica a flexibilidade existente nas relações e na rede de contatos das famílias, enfatizando a importância da família extensa e comunidade no sistema de parentesco brasileiro. Apesar do empenho da mãe de criação em ter guarda de Raquel na sua infância, observou-se a ausência de tal empenho no período de sua adolescência. Ela não buscou o 
desligamento da adolescente, apesar de tê-la criado por muitos anos, e apresentava um discurso estigmatizador relacionado à menina, responsabilizado-a por todos os problemas da família. Esta situação acabou levando à reinstitucionalização da adolescente nove meses após a reinserção.

Nos casos de Pedro e Rosa, apesar de suas famílias possuírem piores condições financeiras do que a família de Raquel, as famílias apresentavam desejo de ter os adolescentes de volta à família, bem como os adolescentes desejavam voltar para casa. Estes dados sugerem que o desejo e a motivação conjunta da família são elementos essenciais para a promoção de uma efetiva reinserção familiar, corroborando estudos de Azor e Vectore (2008). Segundo as autoras, embora a reestruturação financeira seja um elemento importante, o desejo de ter os filhos na família parece ser a mola propulsora para a recuperação da guarda de crianças institucionalizadas.

Quanto ao período de institucionalização, é possível observar a existência de percepções diferentes entre os adolescentes. Rosa e Raquel apresentaram uma percepção positiva sobre o abrigo e o período em que estiveram abrigadas. Elas afirmavam que, no abrigo, além de ter as necessidades básicas atendidas, como alimentação e vestuário, também tinham oportunidades de lazer e educação, que não teriam em suas famílias, e relações de amizade. Esta percepção tem sido evidenciada em diversos estudos atuais, mostrando que o abrigamento pode proporcionar sentimento de proteção e segurança, atuando como um fator de proteção ao desenvolvimento (Arpini, 2003; Silva, 2004; Siqueira, Betts, \& Dell'Aglio, 2006; Siqueira \& Dell'Aglio, 2007). Por outro lado, o enfraquecimento e a falta de continuidade nos relacionamentos de amizade iniciados no abrigo parecem levar a um sentimento de abandono e nova rejeição, pois após o desligamento, parece não haver interesse da instituição, ou de seus membros, em manter contato com os adolescentes desabrigados.

Por sua vez, Pedro afirmava não sentir saudades do pessoal do abrigo, não ter vontade de visitá-los ou manter contato de alguma forma. É possível que esse visível distanciamento e essa imparcialidade, de que a instituição não é algo bom nem ruim, é "normal", pode ser resultado do extenso tempo de institucionalização desse jovem, fazendo com que ele tenha vivenciado mudanças ocorridas pela troca de abrigo e conseqüentes rupturas de vínculo afetivo, com educadores e outras crianças, ao longo de mais de 10 anos. Apesar do ECA (1990) ter preconizado a provisoriedade e o atendimento individualizado na medida de proteção de abrigamento, a realidade de muitas instituições de abrigo no Brasil ainda é semelhante à realidade das antigas instituições totais, nas quais o atendimento oferecido era coletivizado, o período de institucionalização prolongado, não havendo uma preocupação com a individualidade e a conservação de laços familiares (Goffman, 1974; Guirado, 1986). Essas características e condições de atendimento têm sido destacadas na literatura, e podem acarretar prejuízos à população alvo desse atendimento, fazendo com que a institucionalização seja um fator de risco ao desenvolvimento (Goffmam, 1974; Guirado, 1986; Marin, 1999; Weber \& Kossobudzki, 1996). Dessa forma, mesmo que uma melhora nas condições de atendimento nos abrigos tenha sido observada nos últimos anos (Siqueira \& Dell'Aglio, 2006), torna-se necessário avaliar com atenção e cautela cada caso, visto que a percepção de uma criança e adolescente está sob influência de inúmeros fatores, como motivo do abrigamento, condições físicas do abrigo, modalidade de atendimento oferecida, relação entre os abrigados e os educadores/monitores e entre os outros abrigados, entre outros.

Observou-se que, antes do desligamento, os adolescentes realizaram visitas periódicas às suas famílias. Entretanto, tais visitas não faziam parte de um plano e não eram acompanhadas pela equipe técnica dos abrigos. As visitas preliminares ao desligamento têm sido consideradas o cerne de um plano de reinserção familiar, atuando como um "laboratório" no qual os jovens e seus cuidadores aprendem a estar juntos novamente (Davis, Landsverk, Newton, \& Ganger, 1996; Landy \& Munro, 1998; Warsh \& Pine, 2000). São visitas planejadas e que fazem parte de um plano de preservação familiar, possuindo objetivos, que são construídos em conjunto com as famílias. Pesquisas norte-americanas têm indicado os benefícios que um plano de visitação traz para as crianças e adolescentes em cuidados substitutos, tais como sentimento de que os pais/cuidadores os querem na família novamente; elaboração da experiência do afastamento e dos sentimentos acarretados pela separação; e a manutenção dos laços familiares. Simultaneamente ao plano de visitação, oportunidades de aprender estilos de comunicação/ parentalidade e de praticar uma interação familiar saudável são oferecidas para os membros das famílias (Hess \& Proch, 1988). Dessa forma, constata-se que a prática de permitir o encontro entre pais/cuidadores é freqüente nos processos de reinserção analisados. Contudo, visitas realizadas sem acompanhamento e sem engajamento dos familiares não terão os mesmos resultados que visitas planejadas.

Neste estudo, pode-se observar que não foi oferecido às famílias apoio/suporte antes e após da reinserção dos adolescentes, apesar de preconizado pelo art. 94 do ECA (1990). Existiam condições colocadas pela instituição que deveriam ser atendidas, nos casos de Pedro e Rosa, para que os adolescentes pudessem retornar à família e, estando estes critérios cumpridos, os adolescentes foram desligados. Contudo, não existiu uma relação de cooperação e apoio entre as famílias e as equipes dos abrigos; pelo contrário, houve reclamações e queixas das famílias quanto a promessas não cumpridas pelos abrigos. E no caso de Raquel, houve uma ausência de comunicação entre elas. Além disso, parece existir a idéia de que essas famílias não são capazes de educar e cuidar de seus filhos. Algumas instituições têm demonstrado dificuldade em lidar com os familiares das crianças e adolescentes abrigados e com a preservação dos vínculos. Siqueira, Morais, Dell'Aglio e Koller (no prelo) mostraram um descrédito dos dirigentes relacionado aos familiares das crianças abrigadas, sendo estas consideradas "pedaços de família", visto que não conseguem manter ou resgatar os laços afetivos com seus filhos. Segundo Yunes e Szymanski (2003), existe a crença, entre profissionais da Saúde e da Educação, de que a maioria das famílias pobres é acomodada à pobreza, "desorganizada", "comprometida" e "desestruturada", incapaz de superar e reverter a situação de adversidade. Arpini (2003) também aponta que esta percepção faz com que a história de vida, o sofrimento e o sentimento de rejeição sentidos pelos 
abrigados não sejam abordados no contexto institucional, sejam considerados assuntos "velados", dificultando a possibilidade de elaboração do sofrimento e da violência vividos. Certamente, estes fatores, o estigma relacionado às famílias e a prática de promessas que não são cumpridas, não permitem uma verdadeira aproximação entre as famílias e a equipe dos abrigos, dificultam ações conjuntas de promoção do processo de reinserção familiar e o oferecimento de apoio.

Quanto à convivência familiar, Rosa demonstrou estar feliz e ter bom relacionamento com os membros de sua família. A família era chefiada pela irmã de 22 anos, e apesar dos problemas de saúde da mãe e financeiros, além do distanciamento dos outros membros, eles pareciam estar convivendo bem e superando juntos tais problemas. Além disso, a família passou a contar com uma ajuda importante da Igreja da comunidade. $\mathrm{O}$ apoio social tem sido descrito na literatura como um importante fator de proteção, mitigando os efeitos danosos dos fatores de risco e promovendo os processos de resiliência (Samuelsson, Thernlund, \& Ringström, 1996; Sluzki, 1997). No caso de Pedro, o adolescente demonstrou sentir-se pertencente à família de sua tia paterna e à comunidade. As dificuldades na convivência ocorreram em função de Pedro apresentar desinteresse pelos estudos, dificuldades em seguir os horários de seus medicamentos e vontade de ser independente, o que foi interpretado pela tia como uma rejeição pessoal. A adolescência é um período que envolve uma série de transformações físicas, psicológicas e sociais para os indivíduos. Comportamentos tais como busca por identidade adulta, independência, autonomia, comportamento reivindicatório, por exemplo, são características comuns nesse momento (Steinberg, 1993). O comportamento de Pedro pode ser decorrente do fato de ser um adolescente e sua tia demonstrou despreparo para lidar com esses aspectos. Esta situação mostra a importância de um plano de acompanhamento após o desligamento, pois, caso a tia tivesse com quem dividir esses problemas, ela poderia aprender a lidar melhor com a situação, tranqüilizar-se de que tais comportamentos fazem parte do momento que Pedro está vivendo, podendo assim ajudá-lo. Para Raquel, brigas, desentendimentos, descontentamento por parte da mãe de criação faziam parte de seu cotidiano. Contudo, constatou-se que a percepção da mãe de criação era muito mais negativa do que a da adolescente, demonstrando que não só ela não estava preparada para o retorno da jovem como também não estava certa se gostaria desse retorno. Este aspecto confirma a importância de uma avaliação do caso associada à construção de um plano de desligamento em conjunto com a família, evitando que o retorno fracasse.

\section{Considerações finais}

A partir da análise dos três casos de reinserção familiar, foi possível conhecer as características das famílias desses jovens, suas percepções sobre o abrigamento e como esses processos têm sido conduzidos na realidade brasileira. As características observadas nas famílias apontam sua vulnerabilidade social. Estas famílias apresentam fragilidades sociais que interferem nesse processo de reinserção dos filhos. A precariedade econômica tensiona as relações familiares com a entrada de mais um membro, visto que cumprir as necessidades básicas de alimentação, educação e vestuário de mais um membro, para as famílias pobres, é uma tarefa difícil. Assim, o recurso extra do programa social torna-se de grande importância nesse processo, ajudando a suprir essas necessidades básicas. Por outro lado, esse panorama indica que mais do que um recurso extra, que é mínimo e temporário, estas famílias precisam ser profissionalmente preparadas, incluídas em programas de geração de renda e no mercado formal de trabalho.

Apesar de recomendado pelo ECA (1990), dois dos três casos de desligamento não foram avaliados adequadamente $\mathrm{e}$ nem acompanhados pela instituição de abrigo. O único caso que foi acompanhado pelo Serviço de Assistência Social do abrigo ocorreu por existir uma vinculação afetiva entre a profissional e o adolescente, não sendo regra na instituição investigada. Uma das adolescentes retornou ao abrigo cerca de sete meses depois, confirmando, de certa maneira, que este processo foi realizado de forma inadequada. Na prática, não existe um programa de avaliação e acompanhamento de egressos dos abrigos e, muitas vezes, as instituições de abrigo não possuem equipe ou habilitação técnica para realizar este trabalho. A prática de promover visitas periódicas entre os abrigados e seus familiares foi encontrada na totalidade dos casos, contudo, se não forem planejadas em conjunto com as famílias e estas não forem orientadas e ajudadas nesse processo de reconexão, as visitas não serão um importante instrumento para o sucesso na reinserção. De fato, as instituições que possuem assistentes sociais, psicólogos e educadores sociais, parecem realizar esta avaliação e acompanhar o desligamento, entretanto, este trabalho acaba sendo um entre tantos outros que a equipe deve realizar. Existe uma dificuldade para efetivar esta determinação legal em sua plenitude. Assim, diferente do que preconiza o ECA (1990), que atribui ao abrigo a tarefa de promover e acompanhar o desligamento institucional, uma política de reinserção familiar poderia ser criada, com uma equipe formada por assistentes sociais e psicólogos, em parceria com instituições de saúde que já desenvolvem seu trabalho junto a famílias, como o Programa da Saúde da Família (PSF). Esta nova organização, governamental ou não, poderia focalizar especificamente os processos de reinserção familiar, desde a avaliação e preparação das famílias e abrigados, até o acompanhamento posterior dos casos, realizando visitas domiciliares freqüentes e encaminhando-os para programas profissionalizantes e de tratamento de saúde, por exemplo. Estas equipes poderiam ser implementadas através do Sistema Único da Assistência Social, que desenvolve programas e projetos voltados à Proteção Social Básica (prevenção de situação de riscos pessoal e social, fortalecendo a potencialidade das famílias e dos indivíduos) e Proteção Social Especial (voltada à proteção de famílias e indivíduos em situação de risco pessoal e social).

Constatou-se a existência de descontentamento das famílias para com a instituição e o descrédito com relação às equipes dos abrigos para com os familiares dos adolescentes. Este panorama tem sido verificado e deve ser certamente combatido. É necessário o estabelecimento de uma relação aberta e livre de estigmas entre o abrigo e as famílias, possibilitando que as famílias sejam acreditadas no seu esforço de educar seus filhos e que o abrigo não faça promessas as quais não possa cumprir 
devidamente.

É tempo de considerar a questão da reinserção familiar com seriedade e maturidade sociais. É tempo de organizar uma política pública que focalize e privilegie esse processo, contando com profissionais capacitados e desenvolvendo programas objetivos de reinserção familiar. Talvez com a implementação de programas dessa natureza, as famílias não se sentiriam "enganadas" pela instituição e ressentidas frente ao "abandono" social e ao não cumprimento de promessas de ajuda, e muitos casos seriam devidamente acompanhados, resultando no efetivo retorno à família de origem. Conjuntamente com estas políticas, torna-se importante a realização de pesquisas que avaliem a preparação e o andamento desses processos com vistas a compreendê-lo de forma mais integral, contando com amostras de outros estados do Brasil. É tempo de refletir sobre a prática desenvolvida e propor intervenções consistentes no complexo campo da reinserção familiar.

\section{Referências}

Arpini, M. D. (2003). Pensando a perspectiva institucional e a intervenção em abrigos para crianças e adolescentes. Psicologia: Ciência e Profissão, 23(1), 70-75.

Azor, A. M. G., \& Vectore, C. (2008). Abrigar/desabrigar: Conhecendo o papel das famílias nesse processo. Estudos de Psicologia, 25(1), 77-89.

Bellamy, J. L. (2008). Behavioral problems following reunification of children in long-term foster care. Children and Youth Services Review, 30, 216-228.

Berg, B. L. (2001). Qualitative Research Methods for the Social Sciences (4th ed.). Needham Heights, Massachussets: Allyn \& Bacon.

Courtney, M., \& Wong, Y. (1996). Comparing the timing of exits from substitute care. Children and Youth Services Review, 18, 307-334.

Davis, I., Landsverk, J., Newton, R., \& Ganger, W. (1996). Parental visiting and foster care reunification. Children and Youth Services Review, 18, 363-382.

Eamon, M., \& Kopels, S. (2004). "For reasons of poverty": court challenges to child welfare practices and mandated programs. Children and Youth Services Review, 26, 821-836.

Estatuto da Criança e do Adolescente. (1990). Diário Oficial da União. Lei n ${ }^{\circ}$ 8069, de 13 de julho de 1990. Brasília, DF.

Farmer, E. (1996). Family reunification with high risk children: Lessons from research. Children and Youth Services Review, 18, 403-424.

Fonseca, C. (1987). O internato do pobre: Febem e a organização doméstica em um grupo porto-alegrense de baixa renda. Temas IMESC, Sociedade, Direito, Saúde, 4, 21-39.

Goffman, E. (1974). Manicômios, prisões e conventos. São Paulo: Perspectiva.

Guirado, M. (1986). Instituição e relações afetivas: o vínculo com o abandono. São Paulo: Summus.

Hess, P. M., \& Proch, K. O. (1988). Family visiting in out-of-home care: a guide to practice. Washington, DC: Child Welfare League of America Press.

Instituto Brasileiro de Geografia e Estatística. (2002). Censo Demográfico de 2000: Famílias e Domicílios. Obtido em 13/07/2008, de http://www.ibge.gov.br/ home/presidencia/noticias/26122003censofamiliashtml.shtm.

Landy, S., \& Munro, S. (1998). Shared parenting: assessing the success of a foster parent program aimed at family reunification. Child Abuse \& Neglect, $22,305-318$

Maluccio, A., Abramczyk, L., \& Thomlison, B. (1996). Family reunification of children in out-of-home care: research perspectives. Children and Youth Services Review, 18, 287-305.
Maluccio, A. N., Fein, E., \& Davis, I. (1994). Family reunification: research findings, issues and directions. Child Welfare League of America, 73(5), 489-504.

Maluccio, A. N., Warsh, R., \& Pine, B. (1993). Rethinking family reunification after foster care. Community Alternatives: International Journal of Family Care, 5(2), 1-17.

Marin, I. S. K. (1999). Instituições e violência: violência nas instituições. In D. Levisky (Org.), Adolescência pelos caminhos da violência (pp. 101-112). São Paulo: Casa do Psicólogo.

Marsh, J. C., Ryan, J. P., Choi, S., \& Testa, M. F. (2006). Integrated services for families with multiple problems: obstacles to family reunification. Children and Youth Services Review, 28, 1074-1087.

Pine, B., Warsh, R., \& Maluccio, A. N. (1993). Together again: family reunification in foster care. Washington, DC: Child Welfare League of America.

Rizzini, I., \& Rizzini, I. (2004). A institucionalização de crianças no Brasil. Rio de Janeiro: PUC-Rio.

Samuelsson, M., Thernlund, G., \& Ringström, J. (1996). Using the five field map to describe the social network of children: a methodological study. International Journal Behavioral Development, 19, 327-345.

Silva, E. R. (2004). O direito à convivência familiar e comunitária: os abrigos para crianças e adolescentes no Brasil. Brasília: Instituto de Pesquisa Econômica Aplicada/Conselho Nacional dos Direitos da Criança e do Adolescente.

Silva, M. R., \& Nunes, K. S. (2004). Avaliação e diagnóstico do processo de reinserção familiar e social de crianças e adolescentes egressos de uma casa de passagem. Cogitare Enfermagem, 9, 42-49.

Siqueira, A. C. (2006). Instituição de abrigo, família e redes de apoio social e afetivo em transições ecológicas na adolescência. Dissertação de Mestrado, Universidade Federal do Rio Grande do Sul, Porto Alegre.

Siqueira, A. C., Betts, M. K., \& Dell'Aglio, D. D. (2006). Redes de apoio social e afetivo de adolescentes institucionalizados. Interamerican Journal Psychology, 40, 149-158.

Siqueira, A. C., \& Dell'Aglio, D. D. (2006). O impacto da institucionalização na infância e na adolescência: uma revisão de literatura. Psicologia \& Sociedade, 18(2), 71-80.

Siqueira, A. C., \& Dell'Aglio, D. D. (2007). Retornando à família de origem: fatores de risco e proteção no processo de reinserção familiar de uma adolescente institucionalizada. Revista Brasileira de Crescimento e Desenvolvimento Humano, 17(3), 134-146.

Siqueira, A. C., Morais, N. A., Dell'Aglio, D. D., \& Koller, S. H. (no prelo). Experiência das casas lares: Uma alternativa possível para crianças e adolescentes em situação de rua. In N. A. Morais, L. Neiva-Silva \& S. H. Koller (Orgs.), Endereço desconhecido: crianças e adolescentes em situação de rua. Porto Alegre: Casa do Psicólogo.

Sluzki, C. (1997). A rede social na prática sistêmica: alternativas terapêuticas. São Paulo: Casa do Psicólogo.

Steinberg, L. (1993). Adolescence. New York: McGraw-Hill.

Warsh, R., \& Pine, B. (2000). What works in parent-child visiting programs. In M. P. Kluger, G. Alexander \& P. A. Curtis (Orgs.), What works in child welfare (pp. 171-176). Washington, DC: Child Welfare League of America Press.

Weber, L. N. D., \& Kossobudzki, L. H. M. (1996). Filhos da solidão: institucionalização, abandono e adoção. Curitiba: Governo do Estado do Paraná/Secretaria da Cultura.

Yin, R. K. (2005). Estudo de caso: planejamento e métodos. (Daniel Grassi, Trad.). Porto Alegre: Bookman. (Publicado originalmente em 2003).

Yunes, M., A., \& Szymanski, H. (2003). Crenças, sentimentos e percepções acerca da noção de resiliência em profissionais da Saúde e Educação que atuam com famílias pobres. Psicologia da Educação, 17, 119-137. 
Aline Cardoso Siqueira, doutora em Psicologia pela Universidade Federal do Rio Grande do Sul, é Professora Adjunta do Curso de Psicologia/UNIFRA. Endereço para correspondência: Rua Paraíba, 254/202. Santa Maria, RS. CEP: 97060-470. Telefone: (55) 8424-4223/(51) 3308-5470

E-mail: alinecsiq@gmail.com

Ana Paula Couto Zoltowski, é mestranda do Programa de Pós-Graduação em Psicologia/UFRGS.

Jaqueline Portella Giordani, é acadêmica do Curso de Psicologia/UFRGS.

Taíse Mallet Otero, é acadêmica do Curso de Psicologia/UFRGS.

Débora Dalbosco Dell' Aglio, doutora em Psicologia do Desenvolvimento pela Universidade Federal do Rio Grande do Sul, é Professora Adjunta do Programa de Pós-Graduação em Psicologia/UFRGS. 